\title{
Perangkat Lunak Prediktor Pass Satelit
}

\author{
Wellem O. Sineri' ${ }^{1}$, Yohanes Y. Rumbewas ${ }^{2}$, Janne AC. Wejai ${ }^{3}$, Kamirul ${ }^{4}$ \\ Lembaga Penerbangan Antariksa Nasional
}

\begin{tabular}{ll}
\hline Article Info & ABSTRACT \\
\hline Article history: & Stasiun bumi biak merupakan salah satu stasiun pengendali satelit LAPAN \\
Received Jun $12^{\text {th }}, 2021$ & seperti LAPAN-A1 (TUBSAT), LAPAN-A2(ORARI), dan LAPAN-A3 (IPB). \\
Revised Aug $20^{\text {th }}, 2021$ & Setiap harinya, di Balai Kendali Satelit, Pengamatan Antariksa dan Atmosfer, \\
Accepted Aug $31^{\text {th }}, 2021$ & dan Penginderaan Jauh, Biak rutin melaksanakan kegiatan akuisisi data \\
& satelit LAPAN. Untuk melaksanakan hal tersebut, para operator harus sudah \\
Keyword: & merada di ruang kendali satelit sebelum satelit-satelit tersebut lewat guna \\
stasiun bumi & melaksanakan beberapa persiapan terkait kendali satelit. Dalam hal ini, dapat \\
countdown timer & terjadi kesalahan dalam melihat dan membaca jadwal terjadinya pass satelit \\
sdp4, sgp4 & dikarenakan selama ini para operator menggunakan satelit pass prediktor \\
& dari perangkat lunak yang sudah ada namun tidak dilengkapi dengan \\
& countdown timer ataupun alarm. Tujuan dari penelitian ini agar mampu \\
& merancang bangun perangkat lunak prediktor pass satelit yang mampu \\
& memprediksi waktu terjadinya pass atau kemunculan satelit di suatu ground \\
& station. Metode penelitian yang digunakan yaitu pendekatan SDP4 dan SGP4 \\
& merupakan pendekatan (algoritma prediksi) ini, dapat dihitung waktu-waktu \\
& terjadinya pass satelit di lokasi tertentu di bumi beserta lintasan (groundtrack) \\
& satelit tersebut. Berdasarkan permasalahan tersebut maka dilakukan rancang \\
bangun perangkat lunak prediktor pass satelit yang dapat memprediksi dan \\
menampilkan informasi terkait satelit yang akan lewat. Perangkat lunak ini \\
akan dilengkapi dengan fitur countdown timer dan alarm agar operator \\
mendapatkan peringatan dan dapat mempersiapkan kebutuhan sebelum \\
terjadinya pass.
\end{tabular}

Copyright (C) 2021 STMIK Triguna Dharma. All rights reserved.

Corresponding Author: *First Author

Nama : Wellem Obed Sineri

Instansi : Lembaga Penerbangan Antariksa Nasional (LAPAN)

Email: obedsineri@gmail.com

\section{PENDAHULUAN}

Balai Kendali Satelit, Pengamatan Antariksa dan Atmosfer, dan Penginderaan Jauh, Biak merupakan salah satu balai yang bertugas melaksanakan kegiatan akuisisi data house keeping satelit LAPAN-A1, LAPANA2, dan LAPAN-A3. Untuk melaksanakan hal tersebut, para operator harus sudah berada di ruang kendali satelit sebelum satelit-satelit tersebut lewat guna melaksanakan beberapa persiapan terkait kendali satelit. Dalam hal ini, dapat terjadi kesalahan dalam melihat dan membaca jadwal terjadinya pass satelit atau keterlambatan dalam melakukan persiapan dikarenakan selama ini para operator menggunakan satelit pass prediktor dari perangkat lunak yang sudah ada namun tidak dilengkapi dengan countdown timer ataupun alarm sebagai pengingat. Contoh perangkat lunak tersebut adalah SatPC32 dan GPredictor yang hanya menampilkan waktu-waktu terjadinya pass 




(a)

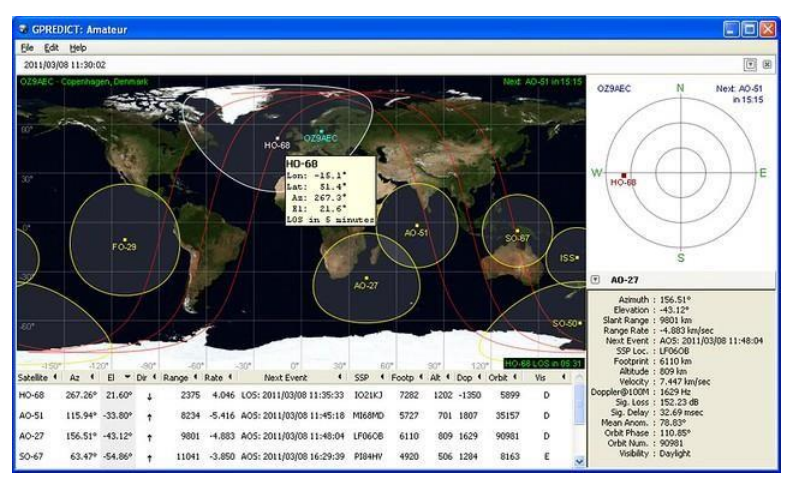

(b)

Gambar 1. (a) Perangkat lunak SatPC dan (b) GPredict, hanya menampilkan informasi pas satelit tanpa adanya countdown timer dan alarm.

Prediksi satelit pass dapat diimplememntasikan melalui beberapa pendekatan beberapa diantaranya adalah pendekatan SDP4 dan SGP4. Melalui pendekatan (algoritma prediksi) ini, dapat dihitung waktu-waktu terjadinya pass satelit di lokasi tertentu di bumi beserta lintasan (groundtrack) satelit tersebut. Informasi terkait waktu lewat satelit dan fitur alarm pada perangkat lunak yang akan dirancang sangat dibutuhkan agar operator dapat tepat waktu dalam mempersiapkan kebutuhan dan pengecekan sebelum satelit lewat seperti kondisi antenna dan perangkat komunikasi ke satelit [1].

Oleh karenanya, akan dilakukan rancangbangun perangkat lunak prediktor pass satelit yang dapat memprediksi dan menampilkan informasi terkait satelit yang akan lewat. Perangkat lunak ini akan dilengkapi dengan fitur countdown timer dan alarm agar operator mendapatkan peringatan dan dapat mempersiapkan kebutuhan sebelum terjadinya pass. Berdasarkan latar belakang masalah yang telah diuraikan di atas, dapat di ambil rumusan masalah sebagai berikut

a. Bagaimana melakukan prediksi waktu terjadinya pass satelit pada stasiun bumi ?

b.Bagaimana melakukan perhitungan countdown timer terhadap terjadinya satelit pass?

c. Bagaimana proses menyalakan alarm penanda persiapan pass akan terjadi dan ketika pass dimulai ?

Tujuan Penelitian

a. Perangkat lunak prediktor pass satelit yang mampu memprediksi waktu terjadinya pass atau kemunculan satelit di suatu ground station. Perangkat lunak ini juga direncanakan mampu menampilkan countdown timer dan menyalakan alarm pada saat terjadinya pass satelit.

b. Mempelajari sistem dan teori yang berkaitan dengan proses prediksi terjadinya pass satelit.

c. Membandingkan kinerja perangkat lunak dengan metode yang sudah ada (terdapat) pada beberapa perangkat lunak lain.

d. Meningkatkan kemampuan SDM yang ada dengan melakukan pengembangan sistem perangkat lunak prediktor pass satelit 


\section{METODE PENELITIAN}

Adapun metoda ataupun tahapan yang direncanakan akan dilakukan untuk merancangbangun perangkat lunak prediktor pass satelit adalah sebagai berikut

a.Menentukan kebutuhan dan spesifikasi perancangan.

Dalam proses pembuatan perangkat lunak prediktor pass satelit dibutuhkan adalah :

a) Perangkat lunak Visual Studio yang sudah terinstal bahasa pemrograman c++

b) Notepad ++

c) Komputer Dekstop

b. Melakukan studi literatur.

Tahapan yang digunakan dalam memprediksi waktu terjadinya pass satelit. Pada metode ini dilakukan untuk merangkum apa saja proses dan tahapan yang harus dilakukan untuk memprediksi pass satelit beserta fitur tambahannya. Secara ringkas, tahapan atau proses yang akan diterapkan pada perangkat lunak Prediktor Pass Satelit ditampilkan pada Gambar 2 berikut :



Gambar 2. Diagram alir proses prediksi pass satelit

c. Pembuatan graphic user interface (GUI)

Adapun proses desain GUI secara keseluruhan perangkat lunak prediktor pass satelit di desain menggunakan 4 (empat) buah modul pendukung yang memiliki fungsi sebagai berikut :

Tabel 1. Modul utama perangkat lunak prediktor pass satelit

\begin{tabular}{|l|l|}
\hline \multicolumn{1}{|c|}{ Nama modul } & \multicolumn{1}{c|}{ Fungsi / Kegunaan } \\
\hline Modul download TLE & $\begin{array}{l}\text { Memperbarui Two Line Element (TLE) melalui jaringan } \\
\text { internet. }\end{array}$ \\
\hline Modul prediksi pass & $\begin{array}{l}\text { Melakukan perhitungan untuk memprediksi waktu } \\
\text { lewat satelit pada suatu ground station (pass) }\end{array}$ \\
\hline Modul countdown timer & $\begin{array}{l}\text { Melakukan penghitungan mundur terhadap terjadinya } \\
\text { suatu pass }\end{array}$ \\
\hline Modul alarm & $\begin{array}{l}\text { Menyalakan alarm penanda persiapan pass akam terjadi } \\
\text { dan ketika pass sedang dimulai. }\end{array}$ \\
\hline
\end{tabular}

d. Penetapan Konfigurasi Pengujian

Pengujian dilaksanakan mengikuti konfigurasi seperti yang ditampilkan pada diagram alir berikut : 


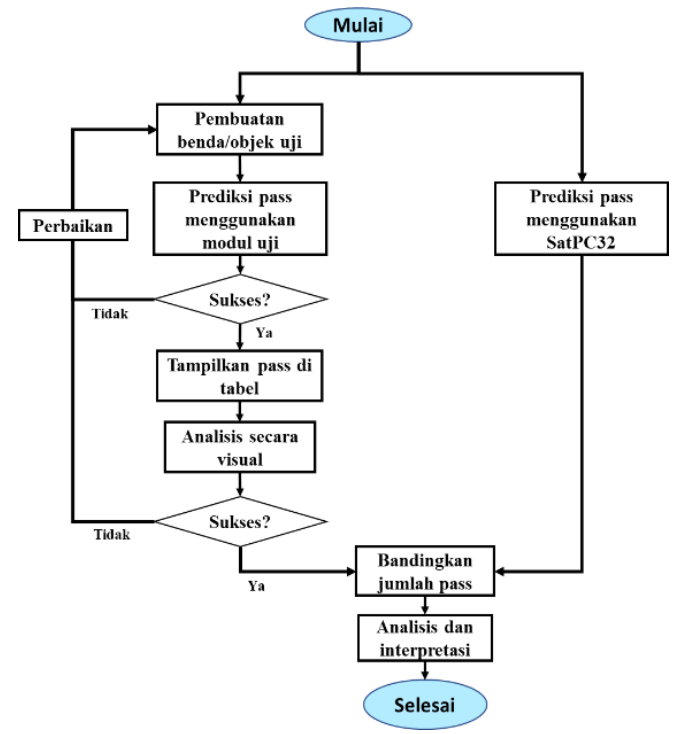

Gambar 3. Konfigurasi/alur yang diterapkan pada proses pengujian modul prediksi pass untuk perangkat lunak prediksi pass satelit.

e. Pembuatan benda uji berupa modul prediksi pass khusus versi pengujian

Modul prediksi pass versi pengujian berbeda dengan modul aslinya dalam hal cara membaca data masukan untuk modul. Pada modul ini, alamat file TLE di komputer, nama satelit, koordinat ground station, serta rentang waktu prediksi dituliskan langsung pada badan program, sedangkan pada modul versi aslinya, masukan ini berupa sebuah variable yang disimpan dalam sebuah file konfigurasi. Tujuan dari pembuatan modul prediksi pass versi pengujian ini adalah untuk mempermudah proses pengujian agar tidak harus melibatkan modul-modul lain di luar modul ini sendiri, karena proses pengujian dilakukan secara spesifik pada modul tertentu (dalam hal ini modul prediksi pass).Berikut ditampilkan cuplikan source code modul prediksi pass versi pengujian [2].

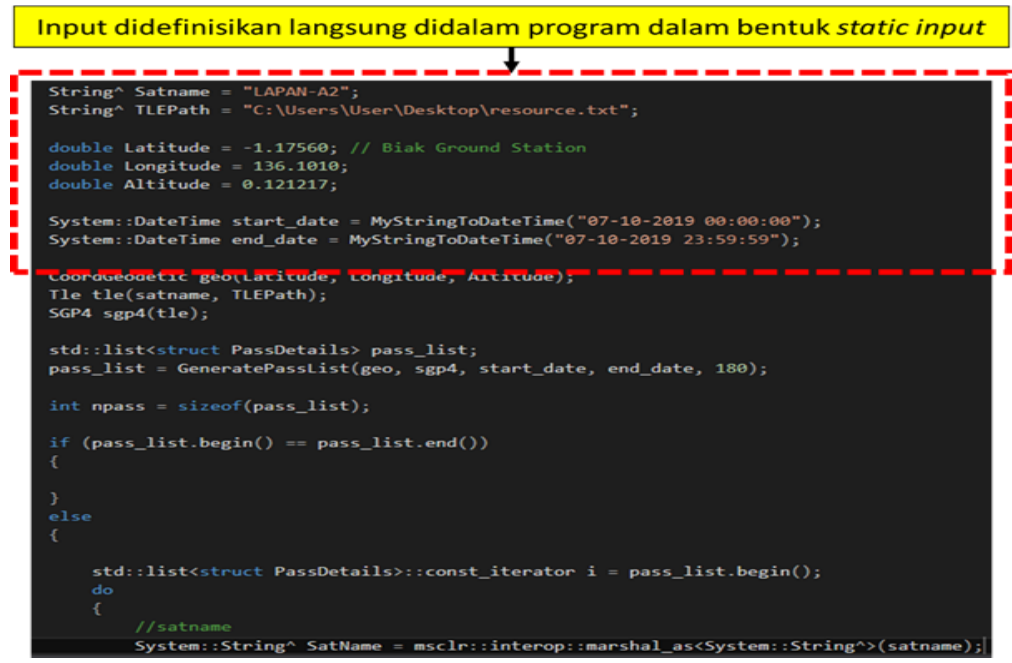

Gambar 4. Cuplikan source code modul prediksi pass versi pengujian.

f. Sistem perolehan dan pengolahan data

a) Data yang akan diperoleh dalam pengujian ini data berupa hasil prediksi pass yang terdiri atas

- Nama Satelit

Jurnal SAINTIKOM Vol. 20, No. 2, Agustus 2021: $64-72$ 
- Elevasi maksimum

- Waktu mulai pass /AOS/Acquisition Of Signal

- Waktu berkahir pass /LOS/Los Of Signal

b) Agar jumlah pass yang dihasilkan oleh modul yang dirancang dan yang dihasilkan oleh SatPC32 dapat dibandingkan, maka dilakukan pengolahan pada data uji yaitu dengan menghitung jumlah pass-nya masing-masing dalam rentang waktu masing-masing 24 jam.

\section{ANALISA DAN HASIL}

\subsection{Modul Prediksi Pass}

Berikut adalah hasil prediksi pass yang telah dihasilkan modul dan berhasil ditampilkan pada tabel. Dari hasil ini, modul menampilkan hasil prediksi. Selain itu, modul juga telah mampu menampilkan data sesuai kolomnya seperti pada Gambar 4. Hasil ini menggunakan satelit LAPAN-A2 sebagai data masukan, stasiun Bumi Biak sebagai ground station, dan merupakan hasil prediksi untuk 13 Oktober 2019.

\begin{tabular}{|c|c|c|c|c|c|c|}
\hline & slist Settin & & & & $\begin{array}{c}- \\
13-1\end{array}$ & $\begin{array}{lr} & \times \\
-2019\end{array}$ \\
\hline & SATELLITE & MAX EL. & AOS - & LOS & DUR. & CODI \\
\hline & LAPAN-A2 & 51.52 & $01: 27: 34$ & 01:41:34 & 14 & BI \\
\hline & LAPAN-A2 & 75.5 & $03: 11: 55$ & $03: 26: 06$ & 14.18 & BI \\
\hline . & LAPAN-A2 & 75.01 & $04: 56: 19$ & $05: 10: 34$ & 14.25 & BI \\
\hline & LAPAN-A2 & 54.88 & $06: 40: 48$ & $06: 54: 59$ & 14.18 & BI \\
\hline & LAPAN-A2 & 46.29 & $08: 25: 19$ & $08: 39: 27$ & 14.13 & BI \\
\hline & LAPAN-A2 & 46.45 & 10:09:49 & 10:23:59 & 14.17 & BI \\
\hline & LAPAN-A2 & 55.35 & $11: 54: 16$ & 12:08:33 & 14.28 & BI \\
\hline & LAPAN-A2 & 75.6 & $13: 38: 40$ & 13:53:04 & 14.4 & BI \\
\hline & LAPAN-A2 & 75.31 & $15: 23: 08$ & $15: 37: 29$ & 14.35 & BI \\
\hline & LAPAN-A2 & 51.68 & $17: 07: 41$ & $17: 21: 49$ & 14.13 & BI \\
\hline & LAPAN-A2 & 39.02 & 18:52:19 & 19:06:10 & 13.85 & BI \\
\hline & LAPAN-A2 & 34.32 & $20: 36: 56$ & $20: 50: 36$ & 13.67 & BI \\
\hline & LAPAN-A2 & 35.82 & $22: 21: 27$ & $22: 35: 08$ & 13.68 & BI \\
\hline & & & & & & , \\
\hline
\end{tabular}

Gambar 5. Modul telah dapat memprediksi dan menampilkan hasil prediksi pass satelit LAPANA2 (13-10-2019) pada tabel yang disediakan.

Hasil perbandingan jumlah prediksi untuk 5 hari (27-31 Oktober 2019) menggunakan modul yang dirancang dan perangkat lunak SatPC32 ditampilkan pada Gambar 5 berikut.

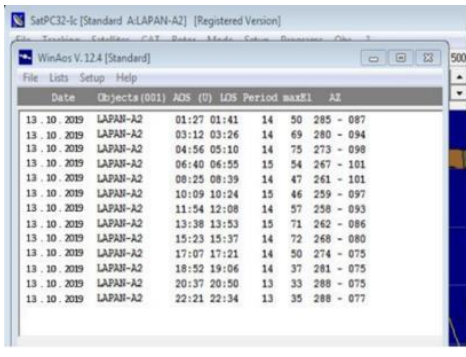

(a)

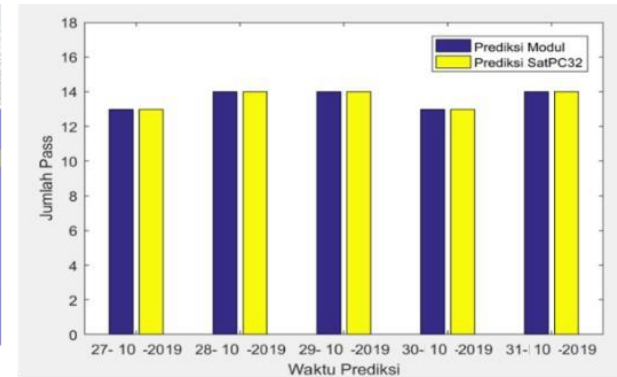

(b)

Gambar 6. (a) Jumlah pass yang dihasilkan SatPC32 pada 13 Oktober 2019 dan (b) Perbandingan jumlah pass yang dihasilkan modul dan SatPC32 pada rentang 5 hari (dipilih rentang tanggal secara acak).

Berdasarkan analisis perbandingan menggunakan jumlah pass pada Gambar 5 diatas, modul yang dirancang menghasilkan jumlah pass yang sama dengan jumlah pass yang dihasilkan oleh perangkat lunak SatPC32.

Dalam melakukan analisis perbandingan jumlah pass, error rata-rata (dalam \%) dapat di hitung dengan persamaaan : 


$$
E=\frac{\sum_{1} \|\left(\frac{\left.\right|_{\text {modul }}-N^{i}{ }_{\text {satpc }} \mid}{N^{i} \text { satpc }} \times 100 \%\right)}{5}
$$

dengan $i=1,2, \ldots, 5$ yang merupakan urutan tanggal (nomor urut hari), $N_{\text {satpc }}$ dan $N_{\text {modul }}$ masing-masing adalah jumlah prediksi pada hari ke-i oleh SatPC32 dan modul yang diuji. Dengan menggunakan persamaan (1) di atas dan menggunakan data yang telah ditampilkan pada Gambar 5(b), maka error jumlah pass yang dihasilkan oleh modul terhadap SatPC32 secara rata-rata adalah 0\% [3], [4].

\subsection{Modul Countdown Timer}

Membuat benda uji berupa modul countdown timer versi khusus untuk keperluan pengujian. Modul ini berbeda dengan modul aslinya dalam hal cara membaca data masukan untuk modul. Karena data masukan pada modul ini berupa sekumpulan pass hasil prediksi, maka kumpulan pass tersebut di-generate langsung di badan program. Sedangkan pada modul aslinya, kumpulan pass diambil pada tabel. Hal ini dilakukan agar pengujian difokuskan pada kemampuan modul dalam menghitung dan menampilkan hasil counting tanpa melibatkan modul dan properti lain (tabel pass). Sehingga, proses analisa dapat difokuskan pada kemampuan modul dalam menghasilkan dan menampilkan hasil counting. Selain itu hasil counting juga akan divalidasi dengan sistem countdown timer online. Online Clock Counter, "Tick Counter : Create your own countdown to any date for free", (https://www.tickcounter.com/) [5].

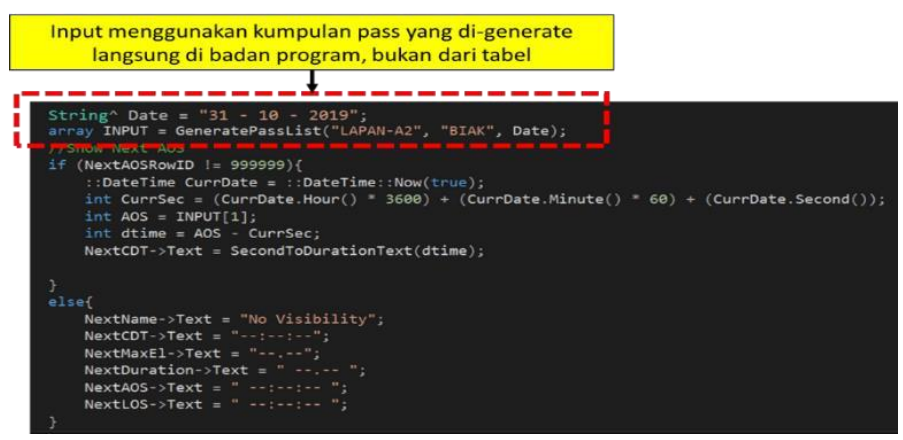

Gambar 7. Cuplikan source code modul countdown timer versi pengujian.

Sedangkan untuk proses validasi, digunakan countdown timer pembanding yang tersedia di www.tickcounter.com, sehingga untuk proses validasi ini sistem penginderaan yang digunakan adalah countdown timer online tersebut, maka data yang akan diperoleh dalam pengujian ini data berupa hasil prediksi pass yang terdiri atas :

a. Counting down timer (data hasil hitung mundur satelit yang akan segera lewat). Data ini didapatkan masing melalui modul yang dirancang dan dari countdown timer online untuk bahan pembanding.

b. Properti satelit yang akan segera lewat :

- Nama Satelit

- Elevasi maksimum

- Waktu mulai pass /AOS/Acquisition Of Signal

- Waktu berkahir pass /LOS/Los Of Signal

- Durasi pass (dalam menit)

c. Dari hasil analisis modul yang dirancang, telah mampu menampilkan hasil counting down beserta properti satelit terkait pada panel yang telah disediakan

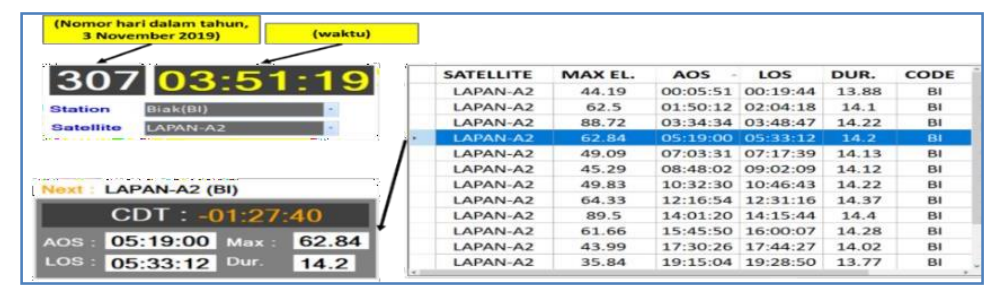

Gambar 8. Modul mampu menampilkan hasil counting down satelit yang akan segera lewat. 
d. Pengolahan data dalam pengujian ini dilakukan pada hasil counting yang masing-masing dihasilkan oleh modul yang dirancang dan dari countdown timer online www.tickcounter.com. Tujuan dari proses ini untuk mengukur seberapa besar error yang dihasilkan oleh modul jika dibandingkan dengan sistem stopwatch online. Persamaan yang digunakan adalah

$$
E=\frac{\left|T_{\text {modul }}-T_{\text {online }}\right|}{T_{\text {online }}} \times 100 \%
$$

Dengan $T_{\text {modul }}$ dan $T_{\text {online }}$ masing-masing adalah hasil counting yang masing-masing dihasilkan oleh modul yang dirancang dan countdown timer online www.tickcounter.com.

e. Dalam melakukan analisis perbandingan hasil counting yang dihasilkan oleh modul dan countdown timer online. Dari hasil analisis, terlihat bahwa modul mampu menghasilkan hitungan yang sama dengan yang dihasilkan oleh conter online seperti ditampilkan seperti pada Gambar berikut

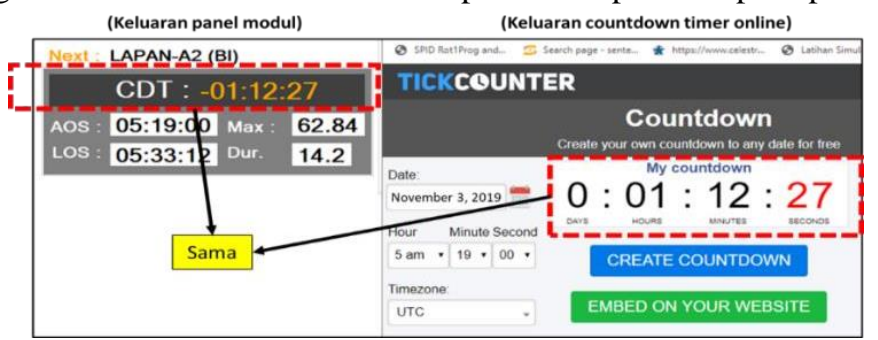

Gambar 9. Salah satu contoh yang menunjukkan bahwa modul mampu menampilkan hasil

hitungan yang sama dengan yang dihasilkan oleh conter online

\subsection{Modul Alarm}

Modul alarm khusus versi pengujian berbeda dengan modul aslinya dikarenakan adanya penambahan source code untuk mendeteksi waktu eksekusi. Dalam hal ini, yang akan dideteksi adalah waktu eksekusi prepass (alarm persiapan) dan current pass (alarm tepat saat satelit mulai lewat). Waktu eksekusi yang dideteksi akan ditampilkan dalam suatu MessageBox sehingga hasilnya dapat dibandingkan dengan waktu yang seharusnya. Dengan membandingkan informasi waktu yang ditampilkan dengan waktu terjadinya pass, maka dapat dihitung selisihnya sebagai indikator apakah alarm telah menyala sesuai dengan waktu yang seharusnya.

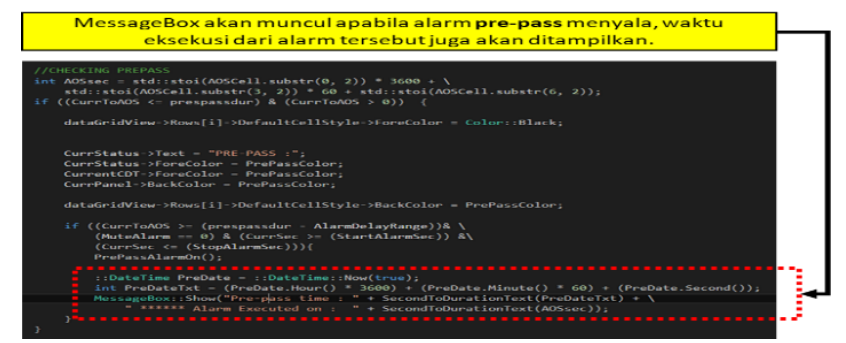

Gambar 10. Cuplikan source code modul alarm pre-pass versi pengujian.

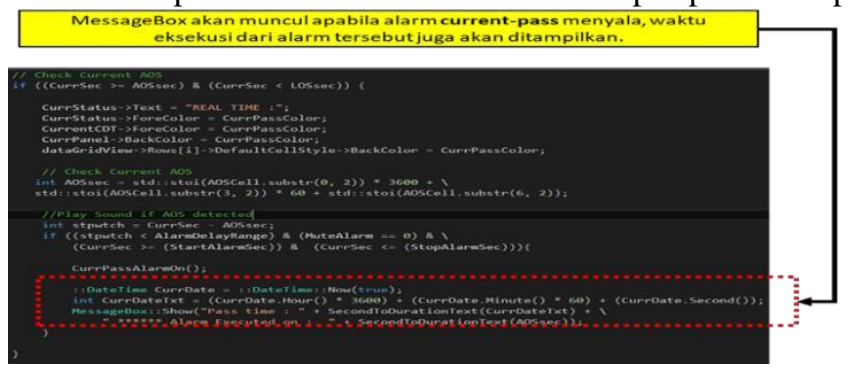

Gambar 11. Cuplikan source code modul alarm current-pass versi pengujian. 
Adapun sistem perolehan dan pengolahan data yang dilakukan dalam proses pengujian ini dijabarkan sebagai berikut

a. Data yang akan diperoleh dalam pengujian ini data berupa hasil pengamatan apakah MessageBox muncul saat alarm menyala. Dalam pengujian ini MessageBox ditampilkan sebagai pengganti bunyi alarm (karena hasil akuisisi bunyi alarm tidak memungkinkan untuk didokumentasikan dan dilampirkan sebagai bahan pelaporan). Oleh kerena itu, kemunculan MessageBox ekivalen dengan tereksekusinya alarm.

b. Pengolahan data dalam pengujian ini dilakukan pada data waktu pre-pass/current-pass dan data eksekusi alarm. Tujuan dari proses ini untuk mengukur apakah alarm menyala tepat pada waktunya. Idealnya, waktu pre-pass ataupun current-pass akan sama dengan waktu eksekusinya masingmasinng. Sehingga, jika ada perbedaan diantara keduanya berarti terdapat error. Dalam pengujian ini, selisih waktu pre-pass dan waktu eksekusinya ( $\left.E_{\text {pre-pass }}\right)$ serta selisih waktu current-pass dan waktu eksekusinya $\left(E_{\text {curr-pass }}\right)$ secara rata-rata dihitung masing-masing menggunakan Persamaan (3) dan (4)

$$
\begin{aligned}
E_{\text {pre-pass }} & =\frac{\sum_{i=1}^{N}\left(\left|T_{\text {pre-pass }}^{i}-T_{\text {execute }}{ }^{i}\right|\right)}{N} \\
E_{\text {curr-pass }} & =\frac{\sum_{i=1}^{N}\left(\left|T_{\text {curr-pass }}^{i}-T_{\text {execute }}^{i}\right|\right)}{N}
\end{aligned}
$$

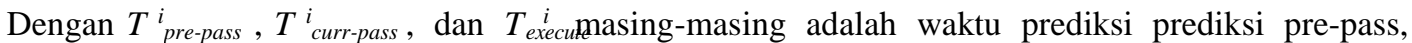
waktu prediksi current- pass, dan waktu eksekusi alarm. Sedangkan $N$ adalah total jumlah pass yang diujicobakan. Dalam pengujian ini, pass yang akan diujicobakan adalah keseluruhan pass satelit LAPAN-A2 pada tanggal 21 November 2019 yang mana berjumlah 14 pass, sehingga $N=14$.

c. Hasil yang ditampilkan oleh modul alarm, mampu menampilkan MessageBox ketika alarm pre-pass dan alarm current pass mulai menyala. Hal ini mengindikasikan bahwa alarm telah dapat menyala pada saat terjadinya pre-pass dan current pass. Pada pengujian ini, alarm pre-p,ass dinyalakan 3 menit sebelum alarm current-pass menyala.

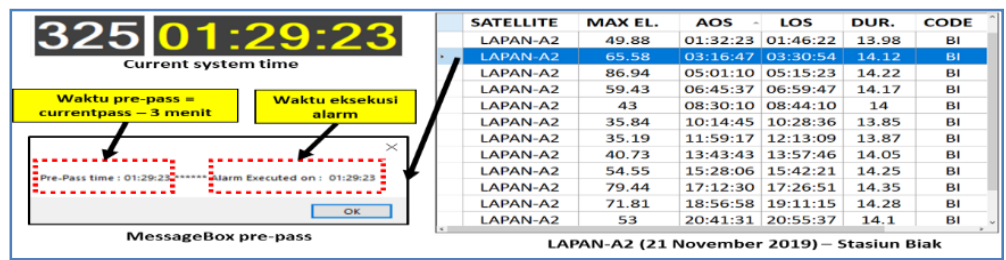

Gambar 12. Modul mampu menampilkan MessageBox saat pre-pass yang dapat dijadikan indikasi bahwa alarm juga telah menyala pada saat tersebut.

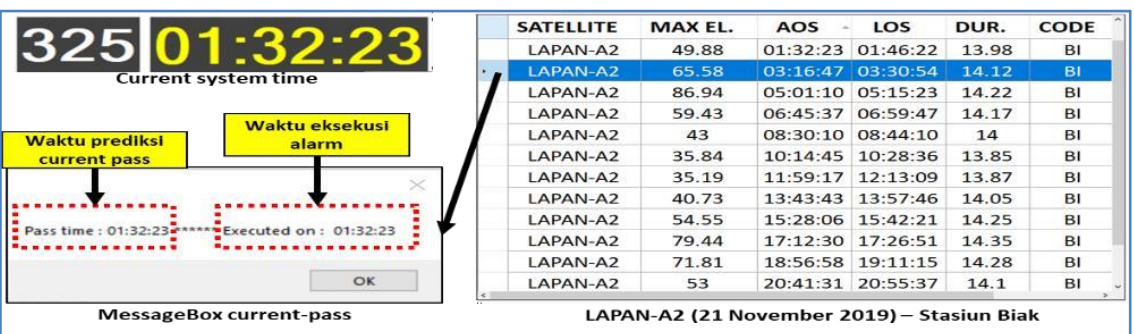

Gambar 13. Modul mampu menampilkan MessageBox saat current-pass yang dapat dijadikan indikasi bahwa alarm juga telah menyala pada saat tersebut.

\section{KESIMPULAN}

Berdasarkan penjelasan diatas, perangkat lunak prediktor pass satelit sangat dibutuhkan agar operator stasiun bumi dapat tepat waktu dalam mempersiapkan kebutuhan dan pengecekan sebelum satelit lewat seperti kondisi antena dan perangkat komunikasi ke satelit. Perangkat lunak ini dilengkapi dengan fitur countdown timer dan alarm agar operator mendapatkan peringatan dan dapat mempersiapkan kebutuhan sebelum terjadinya pass. 


\section{UCAPAN TERIMA KASIH}

Berisikan ucapan terima kasih kepada orang-orang yang mendukung penyelesaian artikel ilmiah ini.

\section{REFERENSI}

[1] http://gpredict.oz9aec.net/-diakses, 19 maret 2019

[2] B. Stroustrup, Programming Principles and Practice Using C++. 2014.

[3] D. A. Vallado and P. Crawford, "SGP4 orbit determination," 2008, doi: 10.2514/6.2008-6770.

[4] B. Eckel, Thinking In C++, vol. 2, Standar. 2017.

[5] Online Clock Counter, "Tick Counter : Create your own countdown to any date for free", (https://www.tickcounter.com/)-diakses 30 oktober - 4 november 2019 